\title{
Sexualidade e prevenção entre homens que fazem sexo com homens nos contextos das pandemias de AIDS e da Covid-19
}

\author{
Sexuality and prevention among men who have sex with men \\ in the contexts of the AIDS and COVID-19 pandemics
}

\footnotetext{
${ }^{1}$ Laboratório de Estudos da Sexualidade Humana do Departamento de Psicologia da Universidade Federal de Pernambuco. Av. Acadêmico Helio Ramos, CFCH, $7^{\circ}$ andar. Cidade Universitária. 50670-901 Recife PE Brasil. lfelipe.rios@gmail.com
}

\begin{abstract}
This essay reflects on sexual practices and prevention in the contexts of the AIDS and COVID-19 pandemics. It analyses data collected between July and October 2020 through participant observation, as part of an ethnographic research project on HIV vulnerability and prevention among men who have sex with men in the Metropolitan Region of Recife, state of Pernambuco (PE), Brazil. The results point to the relevance of physical appearance and the affective bond between partners in engendering emotions that mediate coping with the risk of infection during both pandemics. It indicates the need to incorporate those communicational dimensions into informational materials to make them more effective.
\end{abstract}

Key words Homosexuality, Body stylization, Covid-19, AIDS, Prevention
Resumo Este ensaio reflete sobre práticas sexuais e prevenção nos contextos das pandemias de AIDS e da COVID-19. Analisa dados coletados entre julho e outubro de 2020, por meio de observação participante, no âmbito de uma pesquisa etnográfica sobre vulnerabilidade e prevenção ao HIV entre homens que fazem sexo com homens da Região Metropolitana do Recife. Os resultados apontam para a relevância da aparência corporal $e$ da vinculação afetiva entre os parceiros no engendramento de emoções que medeiam a lida com risco de infecção em ambas as pandemias. Sinaliza para a necessidade de incorporar essas dimensões comunicacionais em materiais informativos, de modo a torná-los mais eficazes.

Palavras-chave Homossexualidade, Estilizações corporais, COVID-19, AIDS, Prevenção, Sexualidade 


\section{Introdução}

Neste ensaio etnográfico, apresenta-se uma reflexão preliminar sobre práticas sexuais e prevenção no contexto da pandemia da COVID-19, doença causada pelo coronavírus da síndrome respiratória aguda grave 2 (Sars-CoV-2 $)^{1}$. Uma das principais medidas de prevenção do Sars-CoV-2 é o distanciamento físico, o que pode impactar nas experiências sexuais das pessoas.

Discutem-se dados coletados no âmbito de uma pesquisa sobre vulnerabilidade e prevenção ao HIV entre homens que fazem sexo com homens (HSHs) da Região Metropolitana do Recife (RMR), cujo campo estava em andamento quando o Brasil tomou as primeiras medidas de enfrentamento à pandemia da COVID-19, em março de 2020.

Embora a pesquisa foque na lida com o infortúnio da infecção pelo HIV, ela não pôde se furtar a abordar a nova dinâmica que se instaurou desde então, e que afetou os espaços de homossociabilidade e a vida sexual dos HSHs. Vale ainda ressaltar que existe uma perigosa sinergia entre as duas epidemias. Conforme a Unaids, as populações-chave para o HIV (dentre elas os HSHs) seriam igualmente vulneráveis para a COVID-19 e a nova pandemia impactaria nas próprias estratégias globais de prevenção e atenção em HIV/Aids².

Em levantamento realizado em julho de 2020 para a elaboração de um projeto sobre práticas sexuais no contexto da COVID-1932, não foram localizadas produções oriundas de pesquisas que explorassem os aspectos antropológicos da sexualidade no contexto da nova pandemia. No entanto, além do documento da Unaids², foram identificados textos, elaborados por organizações governamentais e não governamentais, com foco em sugestões de estratégias de redução de danos nas práticas sexuais, em vistas da infecção pelo Sars-CoV-2. ${ }^{4-6}$

Vale lembrar que as vias aéreas superiores são a porta de entrada do Sars-CoV-2 no organismo humano. O vírus é encontrado na saliva e nas fezes das pessoas infectadas, mas pode ser trazido para o corpo indiretamente, por objetos ou partes do corpo contaminados. Ele consegue sobreviver bastante tempo fora do organismo, a depender da superfície em que ele se encontra. ${ }^{1}$ Mas, sobre as possibilidades de infecção sexual, as informações ainda são vagas. Conforme o New York City Health ${ }^{6}$

We still have a lot to learn about COVID-19 and sex. The virus has been found in the semen and feces (poop) of people with COVID-19. We do not know if COVID-19 can be spread through vaginal or anal sex. We know that other coronaviruses do not easily spread through sex. This means sex is not likely a common way that COVID-19 spreads (p. 1).

Além disso, relações sexuais não se restringem às práticas penetrativas pênis-ânus e pênis-vagina. No contexto da infecção pelo novo coronavírus, duas práticas são bastante problematizadas, o beijo e o sexo oral, uma vez que podem levar o vírus diretamente para a boca.

Os documentos reconhecem a dificuldade de trabalhar a prevenção à Covid-19 a partir da ideia de abstinência sexual. Apostam na perspectiva de oferecer conhecimentos e alternativas que possam ser articulados pelas pessoas para gestão da proteção, apontando o risco de um conjunto de práticas sexuais $^{4-6}$.

As práticas sexuais apresentadas como mais seguras são a masturbação solitária e as mediadas pelas tecnologias de informação e comunicação (TICs), como encontros por vídeo, sexting (troca de conteúdos escritos eróticos por celular), salas de bate-papo, entre outras. Os documentos recomendam que as experiências sexuais sem a mediação das TICs se restrinjam às pessoas que moram juntas, mas ainda assim pontuam a necessidade de higiene corporal e com os objetos, além do uso da máscara ${ }^{4-6}$.

Não obstante, raríssimas pessoas conseguem ficar completamente confinadas por muito tempo. E mesmo as que podem permanecer assim precisam ter acesso a serviços e insumos que vêm de fora das residências. Por isso, é preciso considerar que parceiros sexuais fixos, mesmo morando juntos, podem se infectar e infectar o/a outro/a. Os documentos chamam a atenção para a necessidade da suspensão das práticas sexuais diante do aparecimento de sintomas associados à COVID-19, especialmente o beijo. Prática erótica mais perigosa no contexto da pandemia, a recomendação é de que seja evitado com alguém com quem não se more e com redobrada atenção com alguém que apresente os indicadores de adoecimento (tosse, febre etc. $)^{4-6}$.

Sugerem a diminuição do número de parceiros e a evitação de contato com fluidos e mucosas no sexo. $\mathrm{O}$ uso de barreiras, como camisinha e dental dams, é apontado como medida para diminuir o risco de infecção. Também na linha de reduzir danos é sugerido que os parceiros optem por práticas sexuais que desemparelhem os rostos ${ }^{4-6}$.

Assim, a partir das hierarquizações de riscos e sugestões de como se proteger, acima apresentadas, e das análises sobre a sexualidade e gestão de risco para o HIV dos HSHs da RMR, que passarei 


\section{Notas metodológicas}

A pesquisa se iniciou em 2013 e alternou diferentes técnicas de investigação em seis fases de coletas de dados, conforme apresentado no Quadro 1. As fases foram articuladas em diferentes projetos, aprovados pelo Comitê de Ética em Pesquisa com seres humanos da Universidade Federal de Pernambuco (UFPE).

As interpretações sobre gestão de risco para o HIV, aqui apresentadas, são oriundas das entrevistas realizadas em 2015, em que foram entrevistados dez homens negros, um amarelo e 14 brancos (conforme categorias do IBGE), em sua maioria jovens e adultos jovens (entre 18 e 38 anos). Quatorze entrevistados eram estudantes universitários e, destes, dois trabalhavam formalmente. Os outros assumiam postos de trabalho variados, sem grandes exigências quanto à escolarização e com baixa remuneração.

Empregou-se a análise temática de modo a compreender as categorias "êmicas" utilizadas para descrever as cenas sexuais e o uso do preservativo $^{8,9}$. Foi construído um quadro analítico com os principais temas sobre os contextos em que a camisinha deixou de ser usada e buscou-se as características dos personagens que neles interagiam.

Os dados sobre sexualidade no contexto da COVID-19 foram coletados entre julho e outubro de 2020, por meio de observação participante, e que refletem a compreensão das pessoas e as respostas comunitárias e programáticas à pandemia naquele momento, são do âmbito de

um certo presente etnográfico e assim devem ser compreendidos. Isto é importante de ser dito dada a rapidez da mudança na dinâmica social que envolve a nova pandemia.

Toma-se como material empírico duas cenas etnográficas, e, para dar consistência ${ }^{10}$ à descrição ${ }^{11}$, introduz-se elementos dos contextos sexuais a partir do que aprendi com as narrativas dos muitos entrevistados e minhas próprias observações de campo em outros momentos não tão perigosos $^{12-15}$. A proposta é construir tipos ideais: atribuição de conexões entre elementos identificados nas vivências dos sujeitos, produzindo uma acentuação mental de determinados aspectos da realidade (p. 103) ${ }^{16}$. Conforme Max Weber, os tipos seriam instrumentos analíticos que, ao voltarem a ser confrontados com o mundo da realidade, em novas incursões empíricas pelo campo, permitiriam perceber os caminhos de significação dos atores (coletivos e também individuais) no mundo, no momento em que forem integral ou parcialmente refutados e/ou redescritos.

\section{A lida com o infortúnio do HIV/Aids}

Esta discussão se localiza no campo de estudos das práticas soroadaptativas ao HIV, formas para lidar com o infortúnio de ser infectado, alternativas à gestão individual de risco propostas pela saúde pública. O termo remete ao entendimento de que o aumento do sexo desprotegido para o HIV está relacionado com os muitos anos de convivência com o vírus, a saturação do preservativo como medida exclusiva de proteção e a disseminação de novas evidências e tecnologias biomédicas sobre a transmissão do vírus e o tratamento: hierarquia de risco, tratamento como prevenção $(\mathrm{TcP})$, profilaxias pré e pós-exposição $(\text { PrEP e PEP })^{17,18}$.

No caso brasileiro, o aumento do sexo desprotegido também poderia estar relacionado à saída da prevenção do HIV da ordem do dia, dado o aumento do conservadorismo, em um

Quadro 1. Fases da coleta de dados.

\begin{tabular}{|c|c|l|}
\hline Fase & Período & \multicolumn{1}{c|}{ Atividade } \\
\hline 1 & $2013-2016$ & Observação participante em lugares de homossociabilidade da RMR \\
\hline 2 & 2015 & Entrevista com enfoque biográfico com 25 HSHs \\
\hline 3 & $2016-2017$ & Inquérito comportamental com 380 HSHs \\
\hline 4 & 2016 & Entrevista temática com 24 HSHs participantes do inquérito \\
\hline 5 & $2019-2020$ & Observação participante em lugares de homossociabilidade da RMR, em andamento \\
\hline 6 & $2019-2020$ & Entrevista com enfoque biográfico com 40 HSHs, em andamento \\
\hline
\end{tabular}


falso entendimento de que a epidemia de Aids está vencida ou controlada ${ }^{19}$.

As formas mais comuns de práticas soroadaptativas são o coito interrompido, o soroposicionamento (embasada nas hierarquias de risco, a pessoa escolhe a posição sexual: sexo anal insertivo, sexo anal receptivo ou alternância entre ambas as posições) ${ }^{18,20} \mathrm{e}$ a soroescolha (escolha dos parceiros em função do status sorológico $)^{17,18,21}$.

Tenho pensado os enredos sexuais e os usos de medidas de proteção a partir de um quadro conceitual que busca se aproximar das dimensões mais somáticas dos processos de produção de sentidos. Esses são compreendidos como a própria ação social: a direção tomada pela pessoa, mediante a 1) a apreensão sensorial de um objeto que, 2) instantaneamente, de modo não refletido, 3) mobiliza emoções e 4) significações ${ }^{22}$. Entende-se que o processo de incorporação das instâncias de significação são as múltiplas identificações que realizamos ao longo da vida, com pessoas concretas, com as quais interagimos, e com aquelas que nos são apresentadas por meio das narrativas ${ }^{23}$.

São as narrativas que permitem a uma criança incorporar, por exemplo, o machismo e o racismo, ainda que ela não tenha experiência concreta dessa ordem. Eles se expressam em contos e também nas muitas historinhas sobre o cotidiano que contamos a nossas crianças, na expectativa de ensinar-lhes o certo e o errado das coisas ou de ajudá-las a lidar com infortúnios ${ }^{23}$. Por meio das identificações, as pessoas incorporam as regras sociais, as categorizações de sexo-gênero, classe, raça, sexualidade etc., produzindo figurações. No confronto com novas imagens essas imagos voltarão a ser acionadas, guiando as interações ${ }^{10,24,25}$.

Denomina-se "estilizações corporais" as figurações das classificações inerentes à operação dos supramencionados sistemas socias. São composições sociais resultados estéticos do agenciamento de elementos corporais (constituição física, gestual, vestuário, adorno, sotaque, cheiro, gosto, textura etc). Quando alguém é adscrito a uma estilização por uma configuração imagética, há a produção de sentidos (disposições, significados, valores, emoções) que vão mediar as ações ${ }^{14,15}$.

\section{Na agonia do tesão}

A análise das entrevistas apontou que a soroescolha é a prática soroadaptativa mais relatada. No entanto, apenas um dos entrevistados mencionou a testagem antes da retirada do preservativo e a pactuação de voltarem a utilizá-lo, caso um deles tivesse ou quisesse ter relações fora do casamento. Como em outros contextos ${ }^{17,21,26,27}$, observou-se a existência de práticas de soroescolha presumidas, em que alguns elementos serviam de indicativo para inferir a sorologia de um possível parceiro sexual. Neste âmbito, além de atributos corporais em si, concorriam para a emergência do sexo anal desprotegido (SAD) a vinculação entre os parceiros.

Identificamos três estilizações: "o homem belo, portanto saudável, presumidamente soronegativo para o HIV"; "o homem magro, com a aparência doentia, portanto aidético, presumidamente soropositivo para HIV", e "o homem soropositivo para HIV de aparência saudável”. No campo da vinculação, surgiram personagens como estranho, conhecido, amigo e namorado ${ }^{14}$. Esses personagens funcionavam como integrantes de uma escala, como esquematiza a Figura 1.

Como mostra a Figura 1, quanto mais próximo do polo da direita, mais propensão a não utilizar a camisinha. A justificativa era a de conhecer os hábitos dos parceiros, o que engendraria confiança. Quanto mais para o polo da esquerda, menos se conhecia o parceiro e a confiança diminuía, até desaparecer completamente, na figura do estranho. Como em outros contextos e pesquisas, tesão e amor surgiram como descritores de emoções que produziam a abertura para o SAD, muito atreladas à emoção confiança $a^{27}$. No entanto, cenas de tesão poderiam facilmente desorganizar essa ordenação e dar passagem ao SAD com estranhos ${ }^{14}$. Nesses casos, ficava mais evidente a importância da aparência saudável na composição das estilizações.

Já cheguei a sair numa noite com 19 homens. Eu e mais dois gays [...]. Um menino "comia" meu amigo, aí, depois, vinha pra mim e depois ia pro outro, entendeste? [...] [E vocês chegaram a usar preservativos?] Só teve um só que eu não usei. Porque eu já tava sem saco, já. Mas, com o resto, eu usei. Porque ele eu achei o mais bonitinho, eu achei que ele não tinha doença, não. [...] Aí que tá o processo. A gente achar que, só porque é bonitinho, não tem doença. (Hebert, 24 anos, preto, pintosa, versátil passivo).

O relato de Hebert é engendrado pelas três estilizações que se organizam para produzir, por meio dos corpos, a cena e o enredo de SAD. Quando ele menciona a beleza (logo, aparência saudável) como justificativa para o abandono do preservativo com aquele parceiro da suruba, também está dizendo que não tiraria o preservativo com alguém que figurasse a imagem do aidético. No entanto, quando faz a crítica ao que chama 


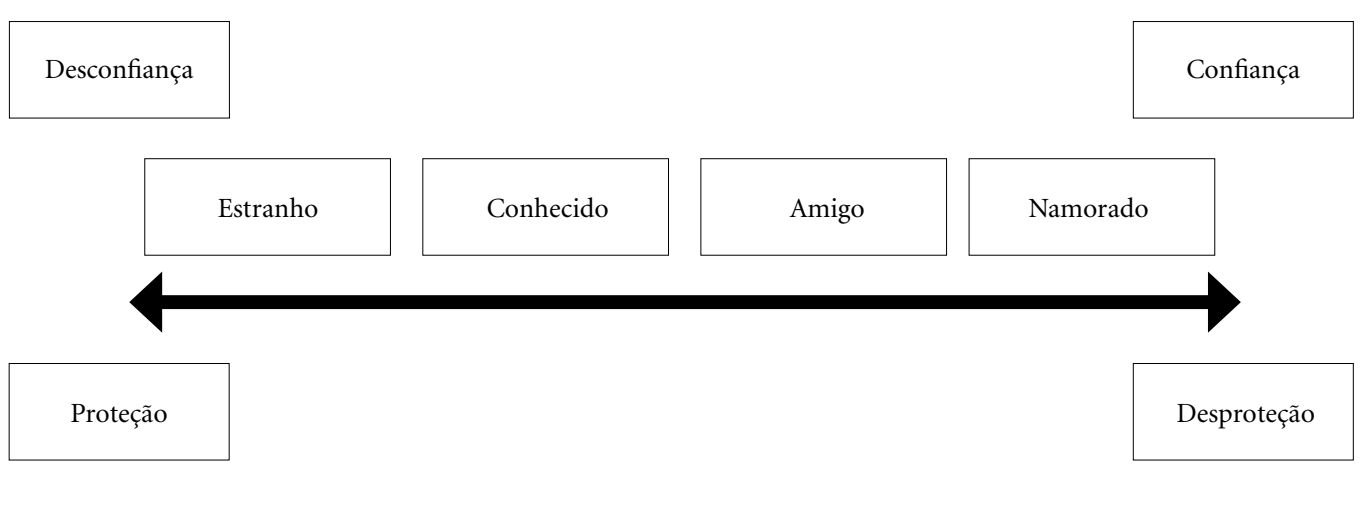

Figura 1. Escala da confiabilidade para retirada da camisinha, conforme vinculação afetiva.

de seu "processo", revela a terceira estilização presente no campo: "o soropositivo de aparência saudável".

As estilizações têm endereçamento na própria história social da epidemia do HIV. Valle ${ }^{28}$ situa a emergência de aidético em 1987, associada com devastação corporal e uma finitude não desejada (p. 185), midiaticamente corporificada pelo cantor Cazuza, que tornou público seu processo de adoecimento e morte: A cara de Cazuza definindo-se como a cara da Aids tornou-se a mais conhecida imagem cultural corporificada de uma vítima da Aids e, sobretudo, de um aidético. (p. 185) Assim, aidético, em contraste com as ideias e imagens de pessoas saudáveis (p. 186), permanece dando sentido às interações sociais.

Já o "soropositivo de aparência saudável" é resultante de dois avanços biomédicos: a ampliação da testagem, que permitiu identificar a presença do vírus antes do adoecimento, e o avanço no tratamento, que possibilitou a postergação e/ou a remissão do adoecimento ${ }^{28}$. Conforme Valle ${ }^{28}$, essa categoria emergiu entre 1991-1992, e, como Cazuza foi para aidético, Magic Johnson, jogador de basquete norte-americano, corporificou a nova categoria: [...] uma combinação de ideias de doença, coragem, força física e saúde. Passou-se a falar dos soropositivos assintomáticos. [...] portadores sadios do vírus, que viviam uma vida normal. Não obstante, completa Valle ${ }^{28}$ : Havia sempre uma sombra na consciência por trás dessa nova representação cultural da saúde no corpo de um doente. Sua identidade funcionava no campo ambíguo de contraste e interação entre saúde e doença (p. 186).

Esse campo de contraste é produtor de mais uma emoção: o medo, que se revela sempre que uma interação sexual com estranhos, amigos ou conhecidos finda ou quando um relacionamento acaba. O medo de ter se infectado faz com que os rapazes procurem a testagem, tão logo se feche a janela imunológica. O teste anti-HIV surge como uma tecnologia biomédica subjetivante ${ }^{29}$ e um ritual de reparação ${ }^{30}$ para pôr fim às incertezas $\mathrm{e}$ dá origem à derradeira emoção do drama do sexo desprotegido: alívio $^{14}$.

\section{Do HIV ao Sars-CoV-2: cenas e riscos}

Do HIV ao Sars-CoV-2, descrevo dois eventos dos quais fiz observações: uma cena em parque público, em Olinda, e indícios sobre o pós-festa no processo de reabertura do Vale das Ninfas, no Centro do Recife. Essas descrições me permitiram alguns elementos para refletir sobre as práticas sexuais e a lida com o infortúnio da Covid-19.

\section{Mascarados no pé da Santa}

A RMR estava no processo de reabertura gradual das atividades econômicas, desde $1^{\circ}$ de junho, depois de 16 dias de lockdown mais rigoroso. Por compromissos religiosos, precisei levar os presentes da deusa para as águas, Oxum, na região comemorada em 16 de julho. Em épocas como a que estamos vivendo, e com uma resposta governamental em nível federal à pandemia de COVID-19 bastante sofrível, marcada por desarticulação, estigmatização e muito descaso com os mais pobres ${ }^{31}$, nunca é demais apelar para a proteção vinda do "outro mundo".

Era domingo, 19 de julho, às dez horas da manhã. O local escolhido para deixar a oferenda foi um parque que se situa entre os municípios 
de Olinda e Paulista, na praia de Rio Doce, local muito aprazível, onde o rio encontra o mar. É um ponto bastante utilizado pelos(as) macumbeiros(as) para suas oferendas. Lá existe uma grande estátua de Iemanjá de frente para o mar, que todos chamam de "a Santa". O afluxo é maior em dezembro, quando, no dia oito, comemora-se a deusa do mar.

Eu e Marcelo, o meu marido, descemos do carro e caminhamos por uma trilha até o rio. A vegetação é rasteira, mas há uma longa extensão de manguezais entre o rio e a pista, impedindo de visualizar da avenida o que se passa em certos trechos do parque. À medida que caminhávamos, observamos uma movimentação de homens mais próximos dos manguezais, mas que não dava para ser vista de onde deixamos nosso automóvel.

Já sabíamos que aquele é um reconhecido ponto de pegação (lugar onde HSHs praticam sexo), só não esperávamos encontrá-lo tão movimentado em um domingo ensolarado. Já estivemos ali antes da pandemia, naquele mesmo horário, para deixar outras oferendas, e nunca o encontramos tão concorrido. Nas outras ocasiões só um entendido (conhecedor dos códigos de homossociabilidade) $)^{13}$ saberia de que se tratava de um ou outro transeunte se embrenhando mangue adentro.

O mais interessante é que a maior parte dos homens estava paramentada para a ocasião. A distância, observamos o recorrente uso da máscara. Quando voltávamos da entrega de nossa oferenda, um rapaz passou e nos cumprimentou. Como nós, ele estava de máscara e, ainda, com uma garrafinha que parecia portar álcool em gel. É importante dizer que, naquele momento, não havia obrigatoriedade de máscaras em espaços públicos, o que só foi regulado por decreto estadual no final daquele mês, em 31 de julho.

Com todos os estabelecimentos comerciais voltados à libertinagem sexual da Região Metropolitana do Recife fechados, parece que recorrer ao parque para o exercício da sexualidade se configurou em uma opção para um número maior de pessoas, haja vista que extrapolava o quantitativo que era de costume em outras ocasiões. No dia seguinte, 20 de julho, os restaurantes e bares começariam a retornar a suas atividades, com novos horários e protocolos. Não voltei ao local para saber se, à medida que a reabertura avançava, a dinâmica da pegação se modificava.

\section{Reabertura no Vale}

Era o segundo domingo de outubro. Fui, às nove horas da manhã, a uma loja de departamentos no centro do Recife, bem perto do Vale das Ninfas - modo como é conhecido a região que abriga a sociabilidade gay no Centro do Recife, cujo epicentro está na esquina entre a avenida Manuel Borba e a rua das Ninfas. O uso de Vale das Ninfas na nomeação da localidade talvez também tenha a ver com a frequência majoritária de jovens à região e com o fato de ali ser um lugar que abriga muitas pintosas (homens femininos). Ali, uma boate e vários bares concorrem entre si e com o comércio ambulante pela clientela de lésbicas, gays, bissexuais, travestis e transexuais, entre outros (LGBTT + ), nas noites quentes dos finais de semana na RMR.

$\mathrm{Na}$ volta para casa, passei propositalmente pela avenida Manuel Borba, onde estão os principais bares e boates. Ao me aproximar dos limites do complexo de entretenimento, olhei imediatamente para o chão, e lá estava o indício de que a noite anterior havia fervido. Pela quantidade de copos descartáveis e guimbas de cigarro (as latinhas certamente foram recolhidas por catadores), não houve a menor condição para o uso das máscaras. Distanciamento social? Muito provavelmente, também não teve como acontecer.

O Miami Pub, extensão da boate Metrópo$l e$, produziu um pequeno pátio externo que até março servia de fumódromo, ao colocar mesinhas e incrementar a decoração. Na sequência, observamos o Conchitas Bar com as portas escancaradas. A impressão é de que estava em processo de limpeza pós-noitada de sábado.

Pelo visto, a crença de que o vírus se foi, do mesmo modo que veio, espalhou-se na comunidade entendida. Na internet, notei que o site "disponível.com" retirou um anúncio de abertura que, desde março de 2020, incentivava usuários a manterem apenas interações online enquanto durasse a pandemia. Há quatro ou cinco semanas (tomando como referência o dia 21/10/2020), e seguindo os passos do plano de abertura traçado pelo Governo do Estado, tenho percebido um relaxamento nas medidas preventivas nos circuitos de homossociabilidade. Recebi pelo WhatsA$p p$ um vídeo em que mostra a animação (muita aglomeração e nada de máscaras) de uma das primeiras noites de reabertura no Vale e, recentemente, um convite para uma pool party em uma chácara em Olinda. A festa estava agendada para 
o final do mês de novembro, mas em outubro já estavam à venda os primeiros lotes de ingresso com desconto. No convite, não há menção à COVID-19 ou medidas sanitárias, e o organizador ainda prometia um abraço apertado nos participantes da festa. A boate Metrópole também já retomou suas atividades, e também apostava em festas na área da piscina. Com bastante antecedência, talvez para se antecipar às festas concorrentes, anunciou no Facebook (/clubemetropole/) seu "tradicional" Halloween:

Se liga no recado: o HALLOWEEN DA METRO vai ser no esquema SOCIAL NA PISCINA!

Aquela superprodução que você já conhece está de volta, adaptada a todos os protocolos de segurança sanitária: por isso, serão TRÊS DIAS de Halloween, com todo o conforto e close que geral já conhece!

\section{Caminhos para prevenção}

Para fins de melhor interpretação, lança-se uma análise desenvolvida a partir de observações nos circuitos de homossociabilidade do Rio de Janeiro ${ }^{12}$. Deste modo, existem:

quatro ordens que se entrecruzam na organização das práticas [eróticas]. Essas ordens, ainda que muitas vezes constituam no espaço social coletivo lugares específicos para as suas realizações, em verdade devem ser pensadas mais como operadores que orientam as práticas. [...] A 'azaração' atravessa todos aqueles espaços, ainda que, no espaço comum das ruas, apareça de forma quase autônoma. Nessa ordem, o sentido corporal mais utilizado é a visão. As sutis trocas de olhares podem sinalizar os desejos e caracterizam os atos da 'pegação'. Uma discursividade gestual que pode dar passagem a 'sarrações', 'bacos' ou 'relacionamentos'. As 'sarrações' [...] ocorrerão onde multidões se aglomeram e podem ser caracterizadas pelas transgressões das regras hegemônicas de proxemia (Alferes, 1987), como uma espécie de invasão dos limites de contato corporais, comuns nas relações cotidianas não-sexuais - sobretudo na percepção que os outros (os que não estão envolvidos na 'sarração') têm das interações que estão observando. [...] [No caso da ordem 'relacionamento'] [...], onde opere, é a possibilidade da palavra que faz com que outras interações sexuais ('azaração', 'sarros' e 'bacos') caminhem para o namoro ou amizade. [...] O 'baco', uma forma condensada de bacanal, se refere ao que em geral se concebe como práticas sexuais (felação, sexo anal etc.), em que duas ou mais pessoas estão envolvidas. Vale salientar que, no sistema erótico, há a primazia de práticas marginalizadas pelos discursos normativos da sexualidade (religiosos, médico etc.). [...] Volto a enfatizar que [...] as práticas sexuais estarão, em maior ou menor grau, atravessadas pelas quatro ordens, ainda que, em determinados locais, nas suas próprias constituições sociossexuais, uma ou outra prevaleça ( $p$. 227-228) $)^{12}$.

Das duas cenas descritas, o fenômeno que me chamou mais atenção foi o uso da máscara em um espaço orgiástico, onde as pessoas vão para o baco $^{12}$, considerando que ainda não havia obrigatoriedade para seu uso. Em dias comuns, a pegação no parque pede por anonimato e discrição. Sobre a vinculação afetiva dos atores, a maciça presença dos estranhos diminui a confiança na saúde de com quem se está interagindo. Talvez por isso mesmo a máscara tenha aparecido com tanta força. Em adição, ela pode até ser percebida como aumentando a discrição.

Para guiar as interações, preponderam os códigos não verbais, que tendem a engendrar cenas de sexo, que fazem e se desfazem com muita agilidade. Salvo exceções, a gestão do tempo nos parques de pegação está relacionada à necessidade de garantir anonimato; assim, não há muito tempo a perder. O importante é encontrar tão rápido quanto possível a satisfação sexual e deixar o local - o que não significa que a pessoa gozará uma única vez no episódio.

O que não é muito comum nos enredos em parque é a presença do beijo na boca, pois isso "entraria na conta" de transar com estranhos. Quanto aos usos sexuais da boca, o mais comum é que as cenas de masturbação resultem, muito rapidamente, no sexo oral boca-pênis. Ao orientar pela imaginação sociológica ${ }^{7}$ diria que, em virtude do uso da máscara, o sexo oral tenha sido descartado pela maioria, mas, do mesmo modo que vemos no cotidiano não sexual, é possível que um ou outro homem tenha abaixado a máscara na altura do queixo e se realizado no pênis de alguém. Na cena ideal, no contexto do uso de máscaras, os atores deveriam ir direto ao ponto: da masturbação ao sexo pênis-anus. Nos parques, posições verticais no sexo anal são as mais comuns, também havendo menor possibilidade de emparelhamento de rostos.

Em um contexto como esse, parece ser mais fácil manter as principais medidas de redução de danos para o Sars-CoV-2 do que, por exemplo, quando duas pessoas, que moram nas residências dos respectivos pais, encontram-se e vão para um motel. No último caso, há possibilidade de realização de uma maior variedade de posições e de práticas, algumas complicadas, quando se pensa 
na eficácia da máscara, em especial aquelas práticas classificadas de preliminares: as sarrações ${ }^{12}$. E quanto mais tempo de sarração, mais suor e mais umidade na máscara, o que diminui sua eficácia.

É bem improvável que o casal permaneça de máscara num quarto de motel, uma vez que estar em relacionamento fixo implica confiança recíproca de que estão seguindo as medidas da prevenção. Na marcação do encontro, certamente amor foi a palavra mais empregada para o convencimento do mais resistente em aceitar o convite. Sub-repticiamente, foi o tesão que realizou a quebra da quarentena.

A partir da imaginação sociológica, nesse caso, as estratégias de prevenção devem passar por estímulo à conversa aberta e sincera sobre os procedimentos mais individuais para se proteger do vírus, no cotidiano de cada um, seria o caminho para discutir medidas factíveis para manter a vida sexual em contexto de pandemia com alguma segurança. O que exigiria por uma autorregulação sobre os principais sintomas, mas também por uma reflexão sobre os assintomáticos (os infectados de aparência saudável).

$\mathrm{O}$ risco dos familiares, residentes com cada um, também deveria ser um tema da conversa, uma vez que o encontro sexual do casal poderia afetar as comunidades de residência. Esses elementos, juntamente com o conhecimento adequado, poderiam ajudar o casal a fazer negociações sobre as medidas mais corretas, como o que realizar e quando, com relação a determinadas posições sexuais.

No caso do Vale das Ninfas, o foco não está propriamente no sexo em si e, mesmo que ocorra a possibilidade, os atores terão que se retirar para um local mais reservado - em cenas parecidas com as descritas, no parque e no motel. A azaração $0^{12}$ em aglomerações na rua, perto de boates e bares, remete à exposição pública e à paquera, portanto são ambientes que pedem posicionamentos estratégicos, de modo que a pessoa possa ver e ser vista. O que não impede que de vez em quando ocorram mãos dadas, abraços, carinhos na cabeça, pernas e costas, bicotas e outras expressões de afeto de maior proximidade corporal entre amigos, muito comum entre os LGBTT+ da RMR. Em certas ocasiões e em certos horários, entretanto, a quantidade de gente por metro quadrado pode fazer com que as interações mudem da azaração para muito próximo da sarração - do friccionar entre os corpos, ainda que mediados pelas roupas.

Sublinha-se, mais uma vez, que nessa cena os amigos e, muitas vezes, namorados são os personagens mais presentes nas composições in- terativas. Ainda que os olhares passeiem pelos estranhos em busca de alguém interessante para, quem sabe, puxar um papo e, em um futuro mais próximo possível, transar e/ou namorar. De todo modo, a presença dos amigos e a confiança que eles engendram certamente diminui a disposição para o uso de máscaras. Sem contar o grande consumo de bebidas e cigarro. Mas como atuar nesse espaço, reforçando os pilares da prevenção à COVID-19?

Esse seria um espaço estratégico para distribuição de materiais educativos. Inspirando-me no que foi produzido nos bons tempos da resposta brasileira à Aids ${ }^{18,19}$, eu sugeriria a produção de um "Kit sobrevivência à COVID-19", à semelhança dos famosos "porta-preservativos" que marcaram a resposta ao HIV/Aids em ambientes festivos. No "Kit", junto aos preservativos e lubrificantes, sachês de álcool em gel e máscaras esterilizadas, prêt-à-porter.

As dimensões do "Kit" deveriam ser suficientes para também caber materiais narrativos, como os que distribuímos ao final das nossas entrevistas no projeto em andamento. Intitulado "Na agonia do tesão", a série de folhetos-cartilha foi produzida a partir da análise sobre as práticas soroadaptativas acima apresentada. Materiais impressos que, a partir de narrativas e imagens, discutem os modos como as emoções e estilos corporais podem induzir a pessoa ao SAD. O primeiro material da trilogia, "Amor e camisinha", trata da negociação do preservativo entre parceiros fixos. O segundo, "Amigos que transam", discute a infecção pelo HIV numa cena sexual entre amigos depois da balada. O terceiro, "Fernando e o urso", aborda a busca pela PEP após uma cena sexual com um desconhecido ${ }^{32}$.

Para a narrativa de um dos folhetos-cartilha que comporiam o "Kit", visualiza-se uma cena de balada com a presença de uma pessoa infectada, mas assintomática. Uma pessoa com máscara sendo estigmatizada pelo uso e por, constantemente, passar o álcool em gel nas mãos. Dez dias depois, ligações telefônicas comentam quais dos amigos se infectaram, e vem a constatação de que somente a mascarada não se infectou. Ainda que muitos dos amigos tenham tido a forma mais fraca da doença e outros permaneçam assintomáticos, um deles está internado na UTI.

Torna-se necessário trazer para campo da reflexão os efeitos do agente etiológico (vírus) e do infortúnio (doença) na vida de alguém como uma forma de produzir identificações e ajudar as pessoas a acreditarem naquilo que não veem, $o$ vírus, de que só teriam consciência corpórea com 
Algumas pesquisas mostram que muitos $\mathrm{HSHs}$ são consumidores de conhecimento biomédi$\mathrm{co}^{33,34}$, o que permitiu, inclusive, a produção do que hoje denominamos práticas soroadaptativas. Algumas delas possuem um grau bastante interessante de eficácia, a ponto de serem incorporadas no próprio cardápio oficial da prevenção combinada para o HIV. ${ }^{35}$ Mas também é preciso considerar que boa parte desse conhecimento é atuado e divulgado corporalmente, nos circuitos de homossociabilidade. Isso ocorre por meio de estilizações que, por exemplo, corporificaram fases do enfrentamento da epidemia, como com as imagens de Cazuza e Magic Johnson.

Assim, a produção de materiais de educação em saúde precisa atualizar essas imagens, narrando-as a partir de perspectivas que transformem o agravo, seu agente etiológico e os personagens dos enredos sexuais em objetos de reflexão; em instrumentos capazes de produzir mudanças nas relações humanas, de modo a mobilizar a empatia, a solidariedade e o cuidado.

\section{Agradecimentos}

À banca examinadora do meu memorial para professor titular do Departamento de Psicologia da UFPE, defendido em dezembro de $2020^{32}$. Este artigo é uma versão do quinto capítulo do memorial, e incorporou as sugestões da banca. Aos pesquisadores do Laboratório de Estudos da Sexualidade Humana, que participaram do processo de coleta dos dados aqui discutidos. Aos integrantes da pesquisa SEXVID ${ }^{3}$, onde sistematicamente temos discutido as questões sexuais da pandemia de COVID-19.

\section{Financiamento}

O artigo contou com apoio financeiro do Conselho Nacional de Desenvolvimento Científico e Tecnológico (CNPq).

\section{Referências}

1. Singhal T. A Review of Coronavirus Disease-2019 (COVID-19). Indian J Pediatr. 2020; 87(4):281-286.

2. Epic (Meeting targets and maintaining epidemic control). Strategic considerations for mitigating the impact of COVID-19 on key-population-focused HIV programs [internet]. Durham (NC): FHI, 2020.

3. Machado P, Mattos A, Prado MA, Rios LF, Campos T. SEXVID: sexualidades e gestão de risco no contexto da pandemia de COVID-19 [projeto de pesquisa]. Porto Alegre: Universidade Federal do Rio Grande do Sul; 2020.

4. Ashm Covid-19. Taskforce report on sexual health services in Australia and New Zealand during the COVID-19 pandemic. Sydney: ASHM; 2020. [cited 2020 Jun 23] Available from: https://ashm.org.au/covid-19/ clinical-care/ashm-covid-19-taskforce-report-on-sexual-health-services/

5. HSE (Health service executive/Ireland). Sex and coronavirus (COVID-19). Dublin: HSE; 2020. [cited 2020 Jun 23] Available from: https://www.sexualwellbeing. ie/sexual-health/sex-and-coronavirus/ 
6. NYC Health. Safer Sex and COVID-19. New York: NYC Health; 2020. [cited 2020 Jun 23] Available from: https://www1.nyc.gov/assets/doh/downloads/pdf/imm/ covid-sex-guidance.pdf

7. Mills C. A imaginação sociológica. Rio de Janeiro: Zahar; 1972.

8. Blanchet A, Gotman A. L'enquête et lês methodes: l'entretien. Paris: Armand Colin; 1992.

9. Minayo C. Análise qualitativa: teoria, passos e fidedignidade. Cienc Saude Colet 2012; 17(3):621-626.

10. Jung C. Fundamentos de Psicologia Analítica. Petrópolis: Vozes; 1985a.

11. Geertz C. A interpretação das culturas. Rio de Janeiro: Guanabara; 1987.

12. Rios L. Parcerias e práticas sexuais de jovens homossexuais no Rio de Janeiro. Cad Saude Publica 2003; 19(Sup. 2):S223-S232.

13. Rios L. Corpos e prazeres nos circuitos de homossociabilidade masculina do centro do Rio de Janeiro. Cienc Saude Colet 2008; 13(2):465-475.

14. Rios L, Albuquerque AP, Santana WJ, Pereira AF, Oliveira Junior CJ. O drama do sexo desprotegido: estilizações corporais e emoções na gestão de risco para HIV entre homens que fazem sexo com homens. Sex Salud Soc 2019; 32:65-89.

15. Rios L, Albuquerque AP, Santana WJ, Pereira AF, Oliveira Junior CJ. Posições sexuais, estilos corporais e risco para o HIV entre homens que fazem sexo com homens no Recife (Brasil). Cienc Saude Colet 2019; 24(3):973-982.

16. Weber M. A objetividade do conhecimento nas ciências sociais. In: Cohn G. Weber. São Paulo: Ática; 1979. p. 79-127.

17. Grace D, Chow SA, Jollimore J, Parry R, Kwag M, Steinberg M, Trussler T, Rekart M, Gilbert M. HIV-negative gay men's accounts of using contextdependent seroadaptive strategies. Cult Health Sex 2014; 16(3):316-330.

18. Ferraz D, Paiva V. Sex, human rights and aids: an analysis of new technologies for HIV prevention in the Brazilian context. Rev Bras Epidemiol 2015; 18 (Supl. 1):89-103.

19. Paiva $\mathrm{V}$, Antunes $\mathrm{M}$, Sanchez $\mathrm{M}$. $\mathrm{O}$ direito à prevenção da aids em tempos de retrocesso: religiosidade e sexualidade na escola. Interface 2020; 24(e180625).

20. Meng X, Zou H, Song Fan, Zheng B, Zhang L, Dai X, Deng M, Zhang X, Lu B. Relative Risk for HIV Infection Among Men Who Have Sex with Men Engaging in Different Roles in Anal Sex: A Systematic Review and Meta-analysis on Global Data. Aids Behav 2015; 19(5): 882-889.

21. Eaton L, Kalichman SC, O'Connell DA, Karchner WD. A strategy for selecting sexual partners believed to pose little/no risks for HIV: Serosorting and its implications for HIV transmission. Aids Care 2009; 21(10):1279-1288.

22. Jung C. Tipos Psicológicos. Petrópolis: Vozes; 1985.

23. Bruner J. Actos de significado: para uma psicologia cultural. Lisboa: Edições 70; 1990.

24. Freud S. Freud (1923-1925) - Obras completas volume 16: O Eu e o Id, Autobiografia e outros textos. São Paulo: Companhia das letras; 2012.

25. Butler J. Cuerpos que Importam. Buenos Aires: Paidós; 2014.
26. Chakrapani V, PJ Boyce, Kavi AR, Newman PA. Contextual influences on condom use among men who have sex with men in India: subjectivities, practices and risks. Cult Health Sex 2013; 5(8):938-951.

27. Antunes M, Paiva V. Territórios do desejo e vulnerabilidade ao HIV entre homens que fazem sexo com homens: desafios para prevenção. Temas Psicol 2013; 21(3):1125-1143.

28. Valle C. Identidades, doença e organização social: um estudo das 'pessoas vivendo com HIV e Aids. Horiz Antrop 2002; 8(17):179-210.

29. Valle CGO. Corpo, doença e biomedicina: uma análise antropológica de práticas corporais e de tratamento entre pessoas com HIV/AIDS. Vivência 2010; 35: 3-51.

30. Turner V. Dewey, Dilthey e Drama: um ensaio em Antropologia da Experiência (primeira parte). Cadernos de Campo 2005; 13: 77-186.

31. Abrucio F, Grin EJ, Franzese C, Segatto CI, Couto CG. Combate à COVID-19 sob o federalismo bolsonarista: um caso de descoordenação intergovernamental. Rev Adm Publica 2020; 54(4):663-677.

32. Rios L. Era uma vez...Memórias de um escutador de histórias interpelado pela pandemia da Covid-19 [memorial para professor titular]. Recife: Universidade Federal de Pernambuco; 2020.

33. De Luiz G. The use of scientific argumentation in choosing risky lifestyles within the scenario of aids. Interface 2013; 17(47):789-802.

34. Nodin N, Leal I, Carballo-Diéguez A. HIV knowledge and related sexual practices among Portuguese men who have sex with men. Cad Saude Publica 2014; 30(11):2423-2432.

35. Brasil. Ministério da Saúde (MS). Diretrizes para a organização dos serviços de saúde que ofertam a profilaxia pré-exposição sexual ao HIV (PrEP) no Sistema Único de Saúde. Brasília: MS; 2017.

36. 'País de maricas': 9 frases de Bolsonaro sobre pandemia que matou 162 mil pessoas no Brasil. BBC News [internet]; 2020 nov 11 [Acessado 2021 jan 04]; Seção Política. Disponível em: https://noticias.uol.com.br/ ultimas-noticias/bbc/2020/11/11/pais-de-maricas9-frases-de-bolsonaro-sobre-pandemia-que-matou162-mil-pessoas-no-brasil.htm?cmpid=copiaecola.

37. Treichler P. AIDS, homophobia and biomedical discourse: an epidemic of signification. Cult Stud 1987; 1(3):263-305.

Artigo apresentado em 07/01/2021

Aprovado em 01/02/2021

Versão final apresentada em 03/02/2021

Editores-chefes: Romeu Gomes, Antônio Augusto Moura da Silva 